\title{
Smoking by High School Students in Kosovo
}

\author{
Zamira Gashi Shatri ${ }^{1,2} \&$ Jeton Shatri ${ }^{3}$ \\ ${ }^{1}$ Faculty of Education, University of Gjakova "Fehmi Agani", Gjakova, Kosovo \\ ${ }^{2}$ Faculty of Education, University of Prishtina"Hasan Prishtina", Prishtina, Kosovo \\ ${ }^{3}$ Faculty of Medicine, University of Prishtina "Hasan Prishtina", Kosovo \\ Correspondence: Jeton Shatri, Faculty of Medicine, University of Prishtina "Hasan Prishtina", Kosovo. E-mail: \\ jeton.shatri@uni-pr.edu
}

Received: December 12, 2018

doi:10.5539/ies.v12n5p49

\author{
Accepted: February 1, $2019 \quad$ Online Published: April 29, 2019 \\ URL: https://doi.org/10.5539/ies.v12n5p49
}

\begin{abstract}
Adolescence is a critical age of change and experiencing, so the influence of social factors in it is very important. The main focus of this research is precisely the elaboration of a negative phenomenon that is very expressed to Kosovar youth, such as smoking. The purpose of the paper is to present how much smoking is present, the factors that influence how much they are aware of the damage they cause, and to make a comparison between the students of two high schools about smoking. Quantitative research was conducted in two high schools in Kosovo including students aged 15-18, both sexes. The realization of the research is done directly with the students. We used the method of theoretical analysis, comparative method and statistical method, as well as questionnaire technique. The main factors affecting smoking are the society, the family, and the personal, also other problems. Based on our research, we can say that this phenomenon is not as worrying as a small number of people consume smoking dominating more males than females. The family (parents) according to them are the main responsibility for preventing this negative phenomenon, then health services, and fewer schools and society.
\end{abstract}

Keywords: smoking, student, school, high school, quantitative research

\section{Introduction}

Smoking is a practice whereby the burning substance results in smoke entering the blood through the breathing. The cigarette is a cigarette cylinder and wrapped paper. During smoking combustion, there are over 4,000 chemical compounds, including nicotine, carbon monoxide, acrolein and other harmful substances (Csordas \& Bernhard, 2013). Smoking causes dependence. People usually start smoking in teens for psychosocial reasons and then become habit affected by its ingredients (Kumar \& Clark, 2005). The purpose of the paper is to present how much smoking is present, the factors that influence how much they are aware of the damage they cause. At the same time, make a comparison between the students of two high schools about smoking.

Department of Health and Human Services $(2010,2014)$ argues that smoking affects almost every body of the body, causes many diseases, and reduces the life expectancy of smokers in general. Tobacco users are disposed to be afflicted with cardiovascular disease by damaging the blood vessels in the heart and the periphery, respiratory system diseases such as lung cancer, chronic obstructive pulmonary disease (COPD)-chronic bronchitis. Smoking can cause cancer anywhere in the body, such as the mouth, throat, larynx, trachea, urinary tract, colon, liver, lobe, pancreas. It can affect the child's failure to develop during pregnancy, in men has harmful effects on spermatogenesis.

In 2008, the World Health Organization called smoking as the biggest cause of death in the world. Based on the adverse effects that affect the human health or the consequences that causes smoking in the students and how much smoking is present. Therefore, this paper is aimed at the awareness of smokers and the population in combating this phenomenon that harms health.

Much research has examined the influence of individual characteristics and characteristics in the immediate social environment (Tyas \& Pederson, 1998; Conrad et al., 1992). Few studies have examined how school characteristics are related to youth smoking behavior (Aveyard et al., 2004).

Recent research has identified two influential school characteristics related to youth smoking. The first is school-level social modeling characteristics (Leatherdale et al., 2005; Maes \& Lievens, 2003). For instance, smoking 
initiation is more likely to occur in schools with higher smoking rates in the senior student population (Cameron et al., 1999). The second is school smoking restrictions. For instance, strong enforcement of school smoking restrictions is related to lower levels of student smoking (Reitsma \& Manske, 2004; Wakefield et al., 2005).

Large differences in smoking prevalence exist between countries and in different environments (i.e., urban vs. rural, socioeconomic classes). In the United States almost $43 \%$ of children aged from 2 months to 11 years of life live in a home with at least one person who is a smoker (Samet \& Yoon, 2001). The prevalence of passive infant smoking was reported to be around $40 \%$ also in Europe (Rodgman \& Perfetti, 2011).

In the United States a number of investigations have attempted to quantify the effects on cardiovascular health in the population of smoking ban policy, for example in New York, a state-wide ban on smoking was found to reduce ETS exposure, incidence of AMIs and strokes, and a decrease in tobacco consumption (McNabola \& Gill, 2009). Studies examining parental smoking bans in the home have found that in households containing non-smokers only that $85 \%$ had a total ban on indoor smoking in place. However $50 \%$ of households with children and one or more smokers present did not have a full indoor smoking ban in place (Pizacani et al., 2003). Hence, smoking ban policies in the workplace in isolation will not protect the entire population and should be used in combination with other tobacco control initiatives such as taxation, early intervention schemes, education and advertising. Promotion of indoor smoking bans in the home to protect children is a key policy area which needs research and implementation (Botelho et al., 2005).

In comparison to adults, children have a higher frequency of breaths per minute, their hepatic metabolism is not yet fully developed and they inhale more air per body weight which explains why children are more susceptible to tobacco smoke exposure (Vitoria et al., 2015).

\section{Method}

The realization of the research is done directly with the students. Questionnaires were conducted in the two upper secondary schools of Kosovo. The following methods were used in this research: theoretical analysis method, comparative method and statistical method.

\subsection{Research Sample}

In this research, a total of 102 students of both sexes are involved. Total girls were surveyed through questionnaires about 45 of them, and men in total 57 students. So in this research are included students aged 15-18 years, i.e. as samples were students of class X, XI and class XII.

\subsection{Instrument and Procedures}

The research was done through a questionnaire. The questionnaire was designed to provide the opinions of students related to using smoking. The questionnaire consisted of questions including demographic information (e.g., gender, the educational level of father/mother, age, household income level monthly). In the student questionnaire, we include these questions as: detection questions, descriptive questions, explanatory questions and evaluation questions. All of the questions were optional. The students were given approximately five minutes to fill out the questionnaire.

\section{Results}

The survey conducted with respondents highlights the number of students who smoke, the factors they influence, how much they are informed about the damages they cause to active and passive smoking smokers. The research results are expressed statistically and are also described in words.

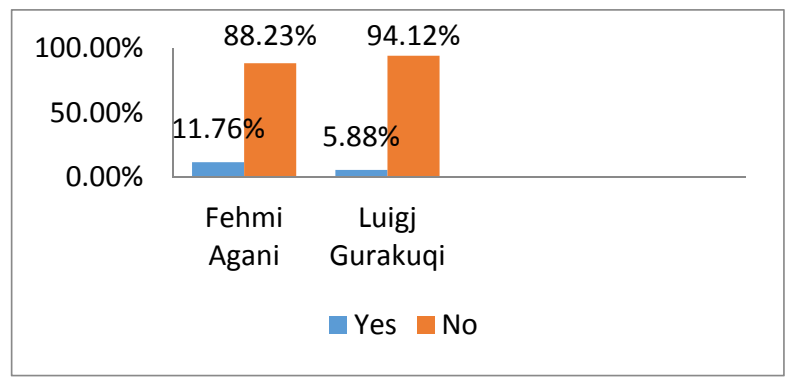

Figure 1. Do you smoke? 
To the question: Do you smoke? from the graph above (Figure 1) it is seen that the largest number are for the Yes option, students of high school "Fehmi Agani", with 11.76\%, while at high school "Luigj Gurakuqi" a total of students who consume tobacco are $5.88 \%$.

But the biggest number who do not smoke is expressed in both schools. At high school "Fehmi Agani" $88.23 \%$ of them do not consume tobacco, while in high school "Luigj Gurakuqi" $94.12 \%$ of the total number of students surveyed.

The question that has been addressed to students who smoke since they started to drink it for the first time, all responded equally have started to smoke from age 13 to 16 years.

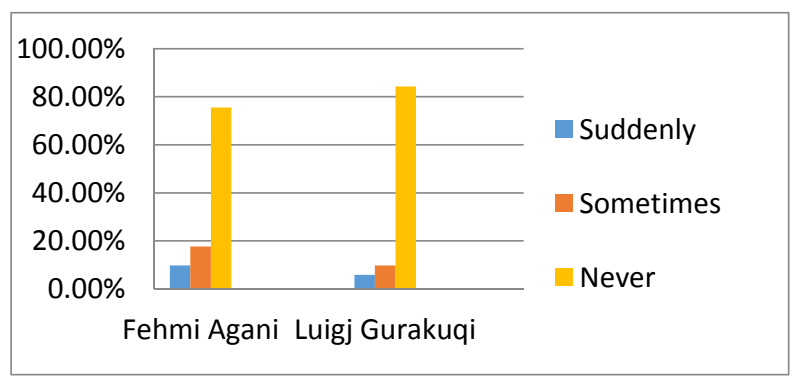

Figure 2. How many times do you smoke?

From Figure 2 it is seen that at high school "Fehmi Agani" consume 5 students or 9.80\%, sometimes 9 or 17.64\%, and those who never smoke are 37 students or $75.54 \%$. Whereas in high school "Luigj Gurakuqi" 3 students or $5.88 \%$ of them are regular consumers, those who have ever responded to 5 or $9.80 \%$ of students, while never smoking 43 or $84.31 \%$ of students.

On the question of whether you have ever had the opportunity to stop smoking? All those students who answered in both schools that smoke are that they have tried to stop smoking.

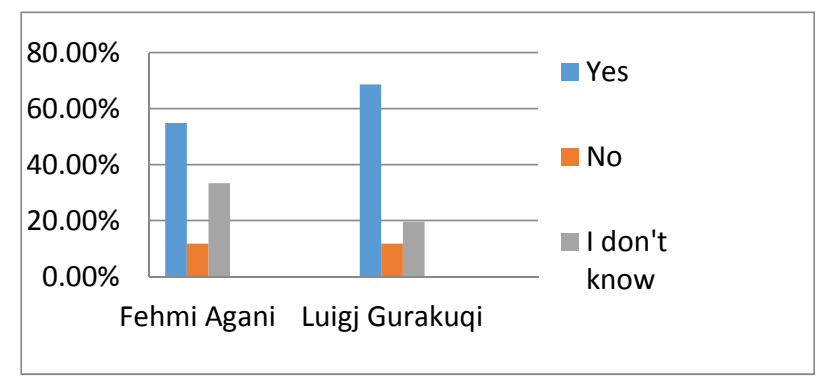

Figure 3. If any of your closest friends offers you to drink a cigarette, will you refuse such a thing even though you do not drink?

From Figure 3, we can see that for high school "Fehmi Agani" 27 or 54.96\% responded that if they were to refuse the cigar if offered to drink, 6 or $11.76 \%$ of the students say they would not, therefore, would not reject it, while 17 or $33.33 \%$ of the respondents responded that they do not know what they would do in this case.

Whereas in high school "Luigj Gurakuqi" 35 or $68.62 \%$ of students say they would refuse, 6 or $11.76 \%$ of them would not refuse the cigar, while 10 or $19.60 \%$ were unspecified or did not answer that question.

Who is the main factor for young people to smoke?

The answers provided by the students of both schools are as follows:

- Society

- $\quad$ Pride or pride

- $\quad$ Frolicking 
- Conflicts at school

- The feeling of smoking at first seems interesting but you cannot stay without it later

- Family Problems

- Parents' carelessness for their children

- No support from the family

- Poor social conditions

- Personal Problems

- $\quad$ Stress

- Dithering

- Yourself and so on.

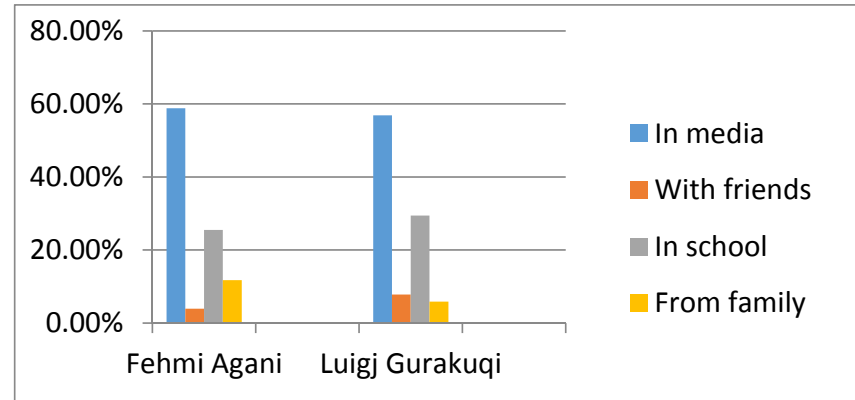

Figure 4. Are you aware of the damage caused by smoking?

Regarding this question how and by whom the students are informed about the damage caused by smoking, both schools have roughly the same answer, i.e. the percentages do not change much (Figure 4).

In the "Fehmi Agani" school, 30 students or $58.82 \%$ responded that they are informed in the media, by friends 2 or $3.92 \%$, of the students at school 13 or $25.49 \%$ of them, and by other sources that the majority of the pupils have been determined for the family that they are informed by it are 6 or $11.76 \%$ of the students.

While in the "Luigj Gurakuqi" high school, students say this: in the media 29 or $56.86 \%$ of students, with friends 4 or $7.84 \%$, in school 15 or $29.41 \%$ of them, while from the family or other sources 3 or $5.88 \%$ of students.

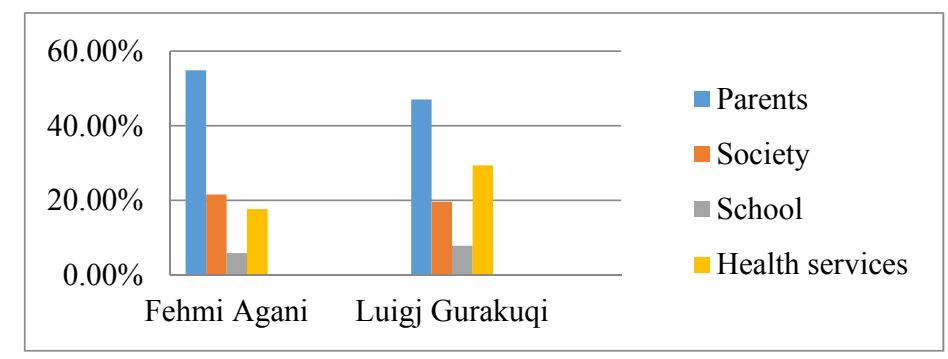

Figure 5. Who do you think is responsible for preventing this negative phenomenon?

Taking into account the question asked to students about who you think is the primary responsibility for preventing this negative phenomenon, the majority of the two schools responded to parents considering that parents are the primary responsibility for preventing this negative phenomenon (Figure 5).

Thus in high school "Fehmi Agani" for the first option i.e. The parents expressed 28 or $54.90 \%$ of the students, 11 students or $21.57 \%$ of the students for the 3 or $5.88 \%$ of the students, while for the health services were 9 or $17.65 \%$ of students. 
While at high school "Luigj Gurakuqi" answers the answers provided by the students of this school are as follows: 24 students or $47.06 \%$ of them answered that the primary responsibility for preventing this negative phenomenon, i.e., the tobacco are the parents, the society responded to 10 students or $19.61 \%$ of them, 4 or $7.84 \%$ of students think of the school. While 15 students or $29.41 \%$ of them think that primary responsibility for student smoking prevention is health services.

\section{Discussion}

According to the WHO report of 2008, only 100 million people died during the 20th century. Currently, about 5.4 million people die each year, and if something is not urgent, then this number will double (WHO, 2008).

In 2012, about $21 \%$ of the world's population aged 15 and over are smokers. Men smoke five times more compared to women respectively $36 \%$ and $7 \%$. Smoking among people over the age of 15 according to WHO was higher in the Western Pacific region, with $48 \%$ of male smokers while among female smokers is higher in the European Region 19\% and 39\% males (WHO). Since smoking is a cause of illness and mortality but it is preventable and seeing that the worst age for its onset is adolescents, then it should be targeted with good policies planned for their anti-tobacco integration and raising awareness about the dangers of smoking (Heras, et.al, 2008).

According to the law on tobacco control in the Republic of Kosovo adopted in 2013, each packaging unit for tobacco products should have the following general remarks:

"Smoking kills" or "Smoking causes premature deaths". Or additional remarks: "Tobacco damages your health", "Smoking causes cancer", "Smoking from pregnant women harms child development", "Smoking causes heart attack and stroke", "Smoking cuts life Yours", "Protect Children: Do not Allow Your Smoke to Smoke”, "Tobacco Makes Skin Aging”, “Smokers Die Young”, "Smoking Cuts Life”. Such remarks in the packs are little aware of the serious problems that can cause smoking, especially young people.

Several studies provide evidence of a causal association between passive smoking in non-smokers and lung cancer or ischemic heart disease (Gan et al., 2007, López et al., 2007; Vineis et al., 2007). A previous study demonstrated that smokers were 21.2 times more exposed, based on nicotine, than non-smokers. A few studies have examined the adverse effects of passive smoking exposure among active smokers.

According to Csordas and Bernhard (2013), the data indicate a prominent role of cigarette-smoke exposure as a modifiable risk factor for precipitating acute cardiovascular events.

McNabola and Gill (2009) suggest that future research into the economic savings in terms of reduction in health costs versus reduction in cigarette excise duty should also be carried out, which could act as a further stimulus for countries still considering the implementation of such a policy.

\section{Conclusion}

Based on the results of this research as well as in the literature, we can conclude that smoking is quite noticeable in youth age, its beginnings are exactly in the adolescent period as a very sensible age. The main factors are society, family, personal and other problems. Based on our research, we can say that this phenomenon is not as worrying as a small number of people consume smoking dominating more males than females. According to them, the tendency is for them to try to leave it, but they must have the support of the family and the society at the same time to have the opportunity to engage in free activities.

For the damage caused by smoking they are more informed by the media and in the school, so it is suggested that more attention be paid to the family, especially to the parents. The family (parents) according to them are the main responsibility for preventing this negative phenomenon, then health services, and fewer schools and society.

\section{Recommendations}

- The introduction and strict application of legislative measures;

- Establishing and implementing restrictive measures in tobacco production;

- Decrease of all subsidies on tobacco production;

- Measures needed to reduce export and import of tobacco;

- Mobilization of all associations: voluntary, medical, humanitarian, humanitarian, and formation of societies and funds for the fight against smoking;

- Stop smoking sales of youth;

- To stop smoking in public places;

- To prohibit the advertising and implementation of other measures. 


\section{References}

Aveyard, P., Markham, W. A., \& Cheng, K. K. (2004). A methodological review of the evidence that schools cause pupils to smoke. Soc Sci Med, 58, 2253-2265. https://doi.org/10.1016/j.socscimed.2003.08.012

Botelho, R., \& Fiscella, K. (2005). Protect Children from Environmental Tobacco Smoke, but Avoid Stigmatization of Parents: A Commentary on Pyle et al. (2005). Families, Systems, \& Health, 23, 17-20. https://doi.org/10.1037/1091-7527.23.1.17

Cameron, R., Brown, K. S., Best, J. A., Pelkman, C. L., Madill, C. L., Manske, S. R., \& Payne, M. E. (1999). Effectiveness of a social influences smoking prevention program as a function of provider type, training method, and school risk. Am. J. Public Health, 89, 1827-1831. https://doi.org/10.2105/ajph.89.12.1827

Conrad, K. M., Flay, B. R., \& Hill, D. (1992). Why children start smoking cigarettes: predictors of onset. Br. J. Addict, 87, 1711-1724. https://doi.org/10.1111/j.1360-0443.1992.tb02684.x

Csordas, A., \& Bernhard, D. (2013). The biology behind the atherothrombotic effects of cigarette smoke. Nat. Rev. Cardiol., 10(4), 219-230. https://doi.org/10.1038/nrcardio.2013.8

Department of Health and Human Services. (2010). Centers for Disease Control and Prevention, National Center for Chronic Disease Prevention and Health Promotion. Office on Smoking and Health.

Department of Health and Human Services. (2014). Centers for Disease Control and Prevention, National Center for Chronic Disease Prevention and Health Promotion. Office on Smoking and Health.

Dolto, F. (2013). Fjalë për adoleshentët ose kompleksi i karavidhes. Ombra CVC.

Gan, Q., Smith, K. R., Hammond, S. K., \& Hu, T.-W. (2007). Disease burden of adult lung cancer and ischaemic heart disease from passive tobacco smoking in China. Tobacco Control, 16(6), 417-422. https://doi.org/10.1136/tc.2007.021477

Heras, P., Konstantinos, K., Antonios, H., Nikolaos, K., \& Dimitrios, M. (2008). Smoking among high school students. Am. J. Drug Alcohol Abuse, 34(2), 219-224.

Kumar, P., \& Clark, M. (2005). Clinical Medicine. London: Elsevier Sounders.

Leatherdale, S. T., Cameron, R., Brown, K. S., \& McDonald, P. W. (2005). Senior student smoking at school, student characteristics, and smoking onset among junior students: A multi-level analysis. Prev. Med., 40(6), 853-859. https://doi.org/10.1016/j.ypmed.2004.09.033

López, M. J., Pérez-Ríos, M., Schiaffino, A., Nebot, M., Montes, A., Ariza, C., ... Fernández, E. (2007). Mortality attributable to passive smoking in Spain, 2002. Tobacco control, 16(6), 373-377. https://doi.org/10.1136/tc.2006.019679

Maes, L., \& Lievens, J. (2003). Can the school make a difference? A multilevel analysis of adolescent risk and health behaviour. Soc. Sci. Med., 56, 517-529. https://doi.org/10.1016/s0277-9536(02)00052-7

McNabola, A., \& Gill, L. (2009.) The Control of Environmental Tobacco Smoke: A Policy Review. Int. J. Environ. Res. Public Health, 6, 741-758. https://doi.org/10.3390/ijerph6020741

Pizacani, B. A., Martin, D. P., Stark, M. J., Koepsell, T. D., Thompson, B., \& Diehr, P. (2003). Household Smoking Bans: Which Households Have Them and Do They Work? Prev. Med., 36, 99-107. https://doi.org/10.1006/pmed.2002.1123

Ratajczak, A., Ratajczak, K., \& Feleszko, W. (2018). A Cross-Sectional Study of Smoking Behaviors and Attitudes of Parents in Pediatric Primary Care Settings. Int. J. Environ. Res. Public Health, 15(7), 1384. https://doi.org/10.3390/ijerph15071384

Reitsma, A. H., \& Manske, S. (2004). Smoking in Ontario schools: Does policy make a difference? Can. J. Public Health, 95(3), 214-218. Retrieved from https://www.jstor.org/stable/41994339

Rodgman, A., \& Perfetti, T. A. (2011). The Chemical Components of Tobacco and Tobacco Smoke. CRC Press, Taylor \& Francis Group. https://doi.org/10.1201/9781420078848

Samet, J. M., \& Yoon, S.-Y. (Eds.) (2001). Gender, women and the tobacco epidemic. Geneva: World Health Organization.

Tyas, S. L., \& Pederson, L. L. (1998). Psychosocial factors related to adolescent smoking: A critical review of the literature. Tob. Control, 7,409-420. https://doi.org/10.1136/tc.7.4.409

Vineis, P., Hoek, G., Krzyzanowski , M., Vigna-Taglianti, F., Veglia, F., Airoldi, L., ... Riboli, E. (2007). Lung 
cancers attributable to environmental tobacco smoke and air pollution in non-smokers in different European countries: A prospective study. Environmental Health, 6(7), 7-10. https://doi.org/10.1186/1476-069X-6-7

Vitoria, P. D., Machado, J. C., Racara, S. B., Araujo, A. C., Samorinha, C., Antunes, H., ... Precioso, J. (2015). Portuguese children's exposure to second-hand tobacco smoke in the family car. Gac. Sanit. 29, 131-134. https://doi.org/10.1016/j.gaceta.2014.10.011

Wakefield, M. A., Chaloupka, F. J., Kaufman, N. J., Orleans, C. T., Barker, D. C., Ruel, E. E. (2005). Effect of restrictions on smoking at home, at school, and in public places on teenage smoking: cross sectional study. $B M J, 321,333-337$. https://doi.org/10.1136/bmj.321.7257.333

\section{Copyrights}

Copyright for this article is retained by the author(s), with first publication rights granted to the journal.

This is an open-access article distributed under the terms and conditions of the Creative Commons Attribution license (http://creativecommons.org/licenses/by/4.0/). 